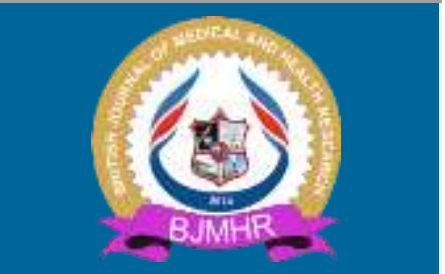

\title{
BJMHR
}

British Journal of Medical and Health Research Journal home page: www.bjmhr.com

\section{A Comparative Study Between Vasopressin Versus Terlipressin In Prevention Of Milrinone Induced Hypotension In Patient Undergoing Cardiac Surgery.}

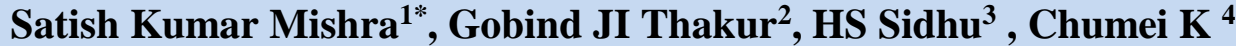 \\ 1.DM Cardiac Anesthesia, Department of Cardiothoracic Anesthesia, Military Hospital \\ (CTC), Pune, Maharashtra, India
}

\begin{abstract}
Milrinone is commonly used during cardiac surgeries to decrease pulmonary arterial pressure. When it is used in inotropic doses it decreases systemic vascular resistance (SVR) and leads to systemic vascular hypotension. This may lead to initiation of vasoconstrictor drugs such as noradrenaline, vasopressin or terlipressin. The aim of the present study was to evaluate and compare the effect of vasopressin versus terlipressin in prevention of milrinone induced hypotension and to see the effect on pulmonary vascular resistance. After obtaining informed written consent \& approval of ethics \& research committee patients who were scheduled for mitral valve replacements (MVR), Aortic valve replacement (AVR), or Dual valve replacement (DVR) with pulmonary arterial hypertension (PAH) were included in the study. Patients were divided into two groups randomly by using a computer generated randomized block design namely group A $(n=20)$ Terlipressin group \& group $B(n=20)$ vasopressin group. 10 minutes after initiation of milirinone after rewarming and weaning from CPB group A patients were started on terlipressin infusion at a rate of $2 \mathrm{ug} / \mathrm{kg} / \mathrm{hr} \&$ group B patients were started on vasopressin infusion at a rate of $0.02 \mathrm{u} / \mathrm{min}$. Infusions in both the groups were continued for 24 hrs in the post-operative period. Hemodynamic measurements were taken at induction of anesthesia, 10 min after start of milrinone infusion, at the end of surgery before shifting the patient to ICU. In the post-operative period these hemodynamic parameters were measured every 6 hourly in the first 24 hrs. At baseline both the systemic \& pulmonary hemodynamic variables were similar in both the groups after the induction of anesthesia, 10 minutes after the initiation of milrinone injection the mean arterial pressure in group A decreased from 77.56 \pm 4.5 to $53.21 \pm 2.1 \&$ in group $b$ it decreased from $76.46 \pm 3.3$ to $52.11 \pm 1.1(p \leq 0.05)$ which was statistically significant in both groups $10 \mathrm{~min}$ after initiation of milrinone which was statistically significant $(p \leq 0.05)$. When the duration of mechanical ventilation, duration of ICU stay and duration of hospital stay were compared between the two groups there was no significant statistical difference between the groups From our study we concluded that when terlipressin is used to treat milrinone induced hypotension it reverses the systemic hypotension with lesser effect on pulmonary vascular resistance when compared to vasopressin
\end{abstract}

Keywords: SVR: systemic vascular resistance, PVR: Pulmonary vascular resistance, MVR: mitral valve replacement, AVR: Aortic valve replacement, DVR: Dual valve replacement PAH: pulmonary arterial hypertension

*Corresponding Author Email: mdsatish08@yahoo.in

Received 05 May 2019, Accepted 19 May 2019

DOI Number:10.21276/BJMHR.2019.6.05.01

Please cite this article as: Mishra S et al., A Comparative Study Between Vasopressin Versus Terlipressin In Prevention Of Milrinone Induced Hypotension In Patient Undergoing Cardiac Surgery. British Journal of Medical and Health Research 2019. 


\section{INTRODUCTION}

Milrinone is a ino-dilator belonging to the class of phosphodiestrase III inhibitors. It is commonly used during cardiac surgeries to decrease pulmonary arterial pressure (1). When milrinone is used in inotropic doses it decreases systemic vascular resistance (SVR) and leads to systemic vascular hypotension. This may lead to initiation of vasoconstrictor drugs such as nor-adrenaline or vasopressin or terlipressin. $(2,3)$. These vasoconstrictor when used are usually non selective and, may lead to increase in both systemic and pulmonary vascular resistance leading to inadvertent increase in pulmonary arterial pressure. Vasopressin (AMP) is a polypeptide which has a disulphide bond between the two cysteine amino acid (4). Vasopressin has a direct vasoconstrictor effect on systemic vascular smooth muscle via V1 receptors (5). Vasopressin has shown to be effective in restoring systemic arterial pressure after septic shock (6), post cardiotomy hypotension (7) \& after off-pump cardiac surgery for milrinone induced hypotension (8)

Terlipressin (TP) is a synthetic analogue of vasopressin and has a greater selectivity for V1 receptors than vasopressin (9) Compared to the vasopressin terlipressin has a longer half-life of 6 hrs.

The aim of the present study was to evaluate and compare the effect of vasopressin versus terlipressin in prevention of milrinone induced hypotension and to see the effect on pulmonary vascular resistance in patient undergoing cardiac surgery.

\section{MATERIALS AND METHOD}

After obtaining informed written consent \& approval of ethics \& research committee patients who were scheduled for mitral valve replacements (MVR), Aortic valve replacement (AVR), or Dual valve replacement (DVR) with pulmonary arterial hypertension (PAH) (RV systolic pressure $>50 \mathrm{~mm}$ of $\mathrm{Hg} /$ mean $\mathrm{PAP}>40 \mathrm{~mm} \mathrm{Hg}$ ) were included in the study. Redo surgery, Emergency surgery, patients with severe hepatic \& renal dysfunction were excluded from the study.

Patients were divided into two groups randomly by using a computer generated randomized block design namely group A $(n=20)$ Terlipressin group \& group B $(n=20)$ vasopressin group. In both the group Under strict aseptic precaution under local anesthesia a wide bore peripheral IV cannula, right radial artery cannulation \& right femoral artery cannulation was done for continuous hemodynamic monitoring. Anesthesia was induced with Inj etomidate $(0.2 \mathrm{mg} / \mathrm{kg})$, Inj fentanyl $(3-5 \mathrm{ug} / \mathrm{Kg}) \& \mathrm{Inj}$ Rocuronium $(0.8-1 \mathrm{mg} / \mathrm{kg})$. After induction of patient right internal jugular vein cannulation was done with 7.5 French triple lumen catheter \& PA catheter was inserted. Anaestheia was maintained with air \& oxygen (50\%), sevoflurane (1-3\%) \& 
Artacurium $(0.5-1 \mathrm{mg} / \mathrm{kg})$. After sternotomy \& heparinisation, CPB was established once ACT was $>420 \mathrm{sec}$.

At the start of rewarming when nasopharyngeal temperature was 34' C milrinone infusion was started at the rate of $0.25 \mu \mathrm{g} / \mathrm{kg} / \mathrm{min}$ without a bolus dose in all patients. Just 10 minutes after initiation of milirinone group A patients were started on terlipressin infusion at a rate of $2 \mathrm{ug} / \mathrm{kg} / \mathrm{hr} \&$ group B patients were started on vasopressin infusion at a rate of $0.02 \mathrm{u} / \mathrm{min}$. The infusions in both the groups were continued for $24 \mathrm{hrs}$ in the post-operative period.

Hemodynamic parameters which were measured included oxygen saturation, heart rate (HR), mean arterial pressure (MAP), central venous pressure (CVP), Mean pulmonary artery pressure (MPAP), pulmonary capillary wedge pressure (PCWP), systemic vascular resistance (SVR), pulmonary vascular resistance (PVR) \& cardiac output (CO). These measurements were taken at induction of anesthesia, $10 \mathrm{~min}$ after start of milrinone infusion, at the end of surgery before shifting the patient to ICU. In the post-operative period these hemodynamic parameters were measured every 6 hourly in the first 24 hrs. Apart from this the duration of mechanical ventilation, ICU stay \& stay in hospital was recorded for all patients.

\section{Statistical Analysis.}

Was done with SPSS software version 17.0 normality of the test were checked using Kolmogorov-smirnov test. The values which were obtained were analyzed \& were expressed as mean $+/$ - standard deviation (SD) and median $+/$ - range. For continuous variables for parametric data, Independent's' test were used and for non-parametric data Mann-Whitney utest were used. For categorical data, Chi-Square test or fisher's exact test were used. A P value $\mathrm{g}<0.05$ was considered to be statistically significant.

\section{RESULTS AND DISCUSSION}

A total of 40 patients were included in the study, group A terlipressin group $(n=20) \&$ group B vasopressin group $(n=20)$. There was no statistically significant difference between the group with regards to demography \& pre-operative clinical data (table 1).

At baseline both the systemic \& pulmonary hemodynamic variables were similar in both the groups after the induction of anesthesia, 10 minutes after the initiation of milrinone injection the mean arterial pressure in group A decreased from $77.56 \pm 4.5$ to $53.21 \pm 2.1 \&$ in group b it decreased from $76.46 \pm 3.3$ to $52.11 \pm 1.1(\mathrm{p} \leq 0.05)$ which was statistically significant in both groups 10 min after initiation of milrinone which was statistically significant $(p \leq 0.05)$. (Table 2).

After initiation of vasopressin infusion there was an increase in MPAP (from 24.1+/-2.3 to $42.3 \pm 2.1)$ at skin closure \& to $38.8 \pm 3.8$ at $24 \mathrm{hrs}(\mathrm{p} \leq 0.05)$. After initiation of terlipressin infusion the increase in MPAP was (from $24.4 \pm 2.6$ to $23.5 \pm 1.4$ ) at skin closure to $19.3 \pm 2.1$ at 
$24 \mathrm{hrs}$ in ICU ( $\leq 0.05)$ (table 2). With regards to PVR there was a significant increase in PVR in vasopressin group compared to terlipressin group (230 \pm 23 vs $130.6 \pm 13$ at end of surgery then $180.3 \pm 32$ vs $110.3 \pm 10$ at 24 hrs post operatively) $(\mathrm{p} \leq 0.05)$.

When the duration of mechanical ventilation, duration of ICU stay and duration of hospital stay were compared between the two groups there was no significant statistical difference between the groups (table 3).

Table 1: Demographic characteristics and clinical data of patients

\begin{tabular}{llll}
\hline & $\begin{array}{l}\text { Terlipressin group } \\
(\mathbf{n = 2 0})\end{array}$ & $\begin{array}{l}\text { Vasopressin group } \\
(\mathbf{n = 2 0})\end{array}$ & $\mathbf{P}$ \\
\hline Age (years) & $40.70 \pm 13.1$ & $36.40 \pm 10.57$ & 0.14 \\
Height (ms) & $166.4 \pm 5.17$ & $163.5 \pm 8.51$ & 0.08 \\
Weight (kg) & $65.71 \pm 11.1$ & $63.85 \pm 13.3$ & 0.44 \\
Right ventricular systolic & $61.2 \pm 9.45$ & $57.5 \pm 8.48$ & 0.50 \\
pressure (mmHg) & & & \\
EF (\%) & $53.28 \pm 4.5$ & $51.2 \pm 4.7$ & 0.53 \\
Left atrial size (mm) & $46.4 \pm 14.1$ & $51.15 \pm 15.1$ & 0.31 \\
Mitral valve replacement (n) & 10 & 9 & 0.57 \\
Aortic valve replacement (n) & 6 & 7 & 0.53 \\
Double valve replacement (n) & 4 & 4 & 0.78 \\
\hline
\end{tabular}

Values are expressed as mean $\pm \mathrm{SD}$ or $\mathrm{n}$ (number of patients). There were no significant differences between the groups $(\mathrm{p}>0.05)$.

SD: Standard Deviation, EF: Ejection Fraction

Table 2: Systemic and pulmonary hemodynamic variables

\begin{tabular}{llll}
\hline & Terlipressin group (n=20) & Vasopressin group (n=20) & P \\
\hline MAP (mmHg) & & & \\
After induction & $77.56 \pm 4.5$ & $76.46 \pm 3.3$ & 0.55 \\
10 min after milrinone & $53.21 \pm 2.1$ & $52.11 \pm 1.1$ & 0.82 \\
At skin closure & $80.05 \pm 6.2$ & $82.15 \pm 5.3$ & 0.70 \\
12 h in ICU & $78.11 \pm 7.3$ & $77.25 \pm 7.5$ & 0.49 \\
24 h in ICU & $86.30 \pm 6.1$ & $85.21 \pm 3.2$ & 0.46 \\
CVP (mmHg) & & & \\
After induction & $6 \pm 2.0$ & $7 \pm 1.0$ & 0.56 \\
After milrinone & $7 \pm 1.0$ & $6 \pm 1.0$ & 0.54 \\
At skin closure & $6 \pm 3.0$ & $7 \pm 1.0$ & 0.70 \\
12 h in ICU & $5 \pm 2.0$ & $6 \pm 1.0$ & 0.65 \\
24 h in ICU & $5 \pm 1.0$ & $5 \pm 2.0$ & 0.85 \\
HR (beat/min) & & & \\
After induction & $77.1 \pm 3.65$ & $77 \pm 4.11$ & 0.82 \\
After milrinone & $86.4 \pm 2.4$ & $88 \pm 2.7$ & 0.95 \\
At skin closure & $77.09 \pm 9.3$ & $78.11 \pm 7.3$ & 0.78 \\
12 h in ICU & $73.12 \pm 4.2$ & $75.15 \pm 2.1$ & 0.54 \\
24 h in ICU & $77.17 \pm 3.2$ & $76.16 \pm 4.2$ & 0.70 \\
MPAP (mmHg) & & & \\
After induction & $58.5 \pm 3.5$ & $60.3 \pm 5.2$ & 0.77 \\
After milrinone & $24.4 \pm 2.6$ & $24.1 \pm 2.3$ & 0.90 \\
At skin closure & $23.5 \pm 1.4$ & $42.3 \pm 2.1$ & $<0.05$ \\
12 h in ICU & $21 \pm 3.1$ & $43.7 \pm 4.6$ & $<0.05$ \\
\hline
\end{tabular}




\begin{tabular}{llll}
\hline $24 \mathrm{~h}$ in ICU & $19.3 \pm 2.1$ & $38.8 \pm 3.8$ & $<0.05$ \\
CO $(\mathbf{l} / \mathbf{m i n})$ & & & 0.77 \\
After induction & $4.0 \pm 0.4$ & $4.1 \pm 0.5$ & 0.86 \\
After milrinone & $5.5 \pm 0.8$ & $5.4 \pm 0.9$ & 0.88 \\
At skin closure & $5.4 \pm 0.9$ & $5.3 \pm 0.7$ & 0.76 \\
$12 \mathrm{~h}$ in ICU & $5.2 \pm 1.0$ & $5.5 \pm 0.7$ & 0.78 \\
$24 \mathrm{~h}$ in ICU & $5.5 \pm 1.0$ & $5.1 \pm 1.0$ & \\
\hline
\end{tabular}

$\mathrm{P}<0.05$ is statistically significant in terlipressin group compared to vasopressin group, $\mathrm{p}<0.05$ is statistically significant in each group compared to baseline reading. Data are expressed as mean \pm SD. MAP: Mean arterial pressure, CVP: Central venous pressure, CO: Cardiac Output, ICU: Intensive care unit, SD: Standard Deviation.

Table 3: Operative and postoperative characteristics and laboratory data

\begin{tabular}{|c|c|c|c|}
\hline & $\begin{array}{l}\text { Terlipressin } \\
(\mathbf{n}=\mathbf{2 0})\end{array}$ & $\begin{array}{l}\text { Vasopressin } \\
(\mathbf{n}=\mathbf{2 0})\end{array}$ & $\mathbf{P}$ \\
\hline $\begin{array}{l}\text { Aortic cross- clamping time } \\
\text { (min) }\end{array}$ & $113.7 \pm 60.5$ & $102.5 \pm 53.6$ & 0.62 \\
\hline Total CPB time (min) & $161.5 \pm 71.55$ & $141.7 \pm 53.66$ & 0.36 \\
\hline \multicolumn{4}{|c|}{ Number of patients requiring vasodilator drug (i.e. nitroglycerine) } \\
\hline During weaning from $\mathrm{CPB}$ & 1 & 1 & 0.90 \\
\hline During ICU stay & 0 & 1 & 0.88 \\
\hline \multicolumn{4}{|c|}{ Number of patients requiring inotropic drug (i.e. epinephrine) } \\
\hline During weaning from $\mathrm{CPB}$ & 3 & 4 & 0.67 \\
\hline During ICU stay & 2 & 2 & 0.72 \\
\hline \multicolumn{4}{|l|}{ Laboratory data } \\
\hline \multicolumn{4}{|l|}{ Blood lactate (mEq/l) } \\
\hline After induction & $1.04 \pm 0.3$ & $1.21 \pm 0.2$ & 0.43 \\
\hline After milrinone & $1.71 \pm 0.3$ & $1.21 \pm 0.2$ & 0.84 \\
\hline At skin closure & $2.29 \pm 0.4$ & $2.30 \pm 0.3$ & 0.75 \\
\hline $12 \mathrm{~h}$ in ICU & $2.06 \pm 0.2$ & $2.25 \pm 0.5$ & 0.65 \\
\hline $24 \mathrm{~h}$ in ICU & $1.66 \pm 0.3$ & $1.58 \pm 0.2$ & 0.56 \\
\hline \multicolumn{4}{|l|}{ Mixed venous oxygen } \\
\hline \multicolumn{4}{|l|}{ Saturation SvO2 (\%) } \\
\hline After induction & $74.2 \pm 3.1$ & $75.7 \pm 2.9$ & 0.46 \\
\hline After milrinone & $73.6 \pm 2.5$ & $74.8 \pm 1.8$ & 0.73 \\
\hline At skin closure & $71.9 \pm 2.7$ & $69.5 \pm 3.1$ & 0.57 \\
\hline $12 \mathrm{~h}$ in ICU & $67.0 \pm 3.4$ & $66.5 \pm 3.1$ & 0.87 \\
\hline $24 \mathrm{~h}$ in ICU & $59.1 \pm 3.1$ & $61.4 \pm 2.7$ & 0.32 \\
\hline $\begin{array}{l}\text { Duration of mechanical } \\
\text { ventilation }\end{array}$ & $13.87 \pm 5.38$ & $11.36 \pm 3.32$ & 0.74 \\
\hline Duration of ICU stay (days) & $4.40 \pm 1.62$ & $4.29 \pm 1.71$ & 0.68 \\
\hline
\end{tabular}

Data are expressed as mean $\pm \mathrm{SD}$ or number of patients, there were no significant differences between the groups $(\mathrm{p}>0.05)$. ICU: Intensive care unit, SD: Standard Deviation, CPB: Cardiopulmonary bypass

\section{DISCUSSION:}

The aim of our study was to evaluate \& compare the effect of vasopressin versus terlipressin in prevention of milrinone induced hypotension in patients undergoing cardiac surgery. In our 
study we found that when milrinone infusion was initiated there was a decrease in both systemic \& pulmonary vascular resistance (SVR \& PVR) with resultant decrease in systemic \& pulmonary pressures. When terlipressin was initiated it increased the systemic vascular resistance (SVR) thereby reverting the systemic vascular hypotension induced by milrinone; with very little effect on pulmonary vascular resistance \& thus mean pulmonary arterial pressure (MPAP). When vasopressin was initiated there was an increase in SVR reverting systemic vascular hypotension \& this was also associated with increase in PVR, compared to terlipressin.

Milrinone is an effective inodialator \& is very effective during weaning from cardiopulmonary bypass because it has a positive inotropic action and also it reduces SVR \& PVR thus providing adequate cardiac performance in patients with residual pulmonary hypertension after cardiac surgery (10).

Milrinone induced systemic hypotension should be treated promptly $\&$ an ideal drug would be one which will increase the SVR with minimal effect on PVR. Both vasopressin \& terlipressin are used in this scenario, when compared to vasopressin; terlipressin has a greater selectivity for V1 receptor \& therefore have a stronger vasopressor effect. Apart from this terlipressin has a longer duration of action compared to vasopressin (half-life of vasopressin is 24 min \& that of terlipressin is $6 \mathrm{hrs}$ ) (11). Therefore terlipressin is more specific in term of increasing SVR \& has a minimal effect on PVR as compared to vasopressin.

Conclusion: From our study we concluded that when terlipressin is used to treat milrinone induced hypotension it reverses the systemic hypotension with lesser effect on pulmonary vascular resistance when compared to vasopressin

\section{REFERENCES}

1. Oztekin I, Yazici S, Oztekin DS, Goksel O, Issever H, Canik S, et al. Effects of lowdose milrinone on weaning from cardiopulmonary bypass and after in patients with mitral stenosis and pulmonary hypertension. Yakugaku Zasshi 2007;127:375-83.

2. Vlahakes GJ, Turley K, Hoffman JI. The pathophysiology of failure in acute right ventricular hypertension: Hemodynamic and biochemical correlations. Circulation $1981 ; 63: 87-95$.

3. Belenkie I, Horne SG, Dani R, Smith ER, Tyberg JV. Effects of aortic constriction during experimental acute right ventricular pressure loading. Further insights into diastolic and systolic ventricular interaction. Circulation 1995;92:546-54.

4. Barberis C, Mouillac B, Durroux T. Structural Bases of Vasopressin/Oxytocin Receptor Function. J Endocrinol. 1998;156:223-229. 
5. Thibonnier M, Roberts JM. Characterization of Human Platelet Vasopressin Receptors. J Clin Invest. 1985;76:1857-1864.

6. Landry DW, Levin HR, Gallant EM, Seo S, D'Alessandro D, Oz MC, et al. Vasopressin pressor hypersensitivity in vasodilatory septic shock. Crit Care Med 1997;25:1279-82.

7. Talbot MP, Tremblay I, Denault AY, Bélisle S. Vasopressin for refractory hypotension during cardiopulmonary bypass. J Thorac Cardiovasc Surg 2000;120:401-2.

8. Jeon Y, Ryu JH, Lim YJ, Kim CS, Bahk JH, Yoon SZ, et al. Comparative hemodynamic effects of vasopressin and norepinephrine after milrinone-induced hypotension in offpump coronary artery bypass surgical patients. Eur J Cardiothorac Surg 2006;29:9526.

9. Leung FW, Jensen DM, Guth PH. Endoscopic Demonstration That Vasopressin but Not Propranolol Produces Gastric Mucosal Ischaemia in Dogs with Portal Hypertension. GastrointestEndosc. 1988;34:310-313.

10. Wang H, Gong M, Zhou B, Dai A. Comparison of inhaled and intravenous milrinone in patients with pulmonary hypertension undergoing mitral valve surgery. Adv Ther 2009;26:462-8.

11. Scharte M, Meyer J, Van Aken H, Bone HG. Hemodynamic effects of terlipressin (a synthetic analog of vasopressin) in healthy and endotoxemic sheep. Crit Care Med 2001;29:1756-60.

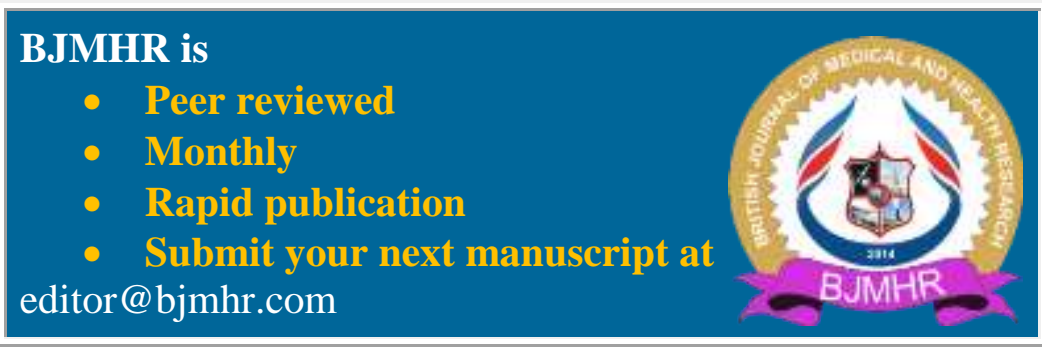

